\title{
THE PROVISION OF PASTURE LEGUMES FOR DIFFICULT ENVIRONMENTS
}

R.L. BURT and M.B. FORDE

Division of Tropical Crops and Pastures, CSIRO,

Townsville, Queensland 4814, Australia

Grasslands Division, DSIR, Palmerston North, New Zealand

\section{Abstract}

Early plant introduction in Australia and NZ involved familiar European species and simple general principles. 'First-generation' pasture cultivars in both countries were based on naturalized or cultivated material originally brought by colonists. Later, imported material was systematically used to improve these established varieties and produce 'second-generation' cultivars more closely adapted to local ecological conditions and agronomic systems. This simple approach proved inadequate for new and difficult environments which required different types of plant, and new species were sometimes tried and discarded prematurely because their potential was not fully displayed in the limited material initially available. Experience with Stylosanthes in Australia shows that full suites of germplasm are necessary to evaluate a new species properly, and that such material should be deliberately and systematically collected from areas of similar or more extreme climate, particular attention being paid to edaphic characteristics. To obtain suitable legumes for the cold dry high country of the South Island collections from homologous regions in places such as Chile, Argentina, Kashmir, and the USSR may be useful.

Keywords: plant introduction, Stylosanthes, Lotus, South America, Australia, New Zealand

\section{INTRODUCTION}

Many millions of years ago Australia and New Zealand became separated from those parts of the world which were to produce most of the important pasture species. Clovers, ryegrasses and so forth are not native to Australasia, and their introduction and domestication have been matters of national importance. Why might work in Australia, especially that in the tropics, be expected to contribute here?

There are two reasons why this may be so. First, everyone makes mistakes, and these become obvious with the benefit of hindsight; the introduction of noxious weeds and our attempts to assess the value of a pasture species on a limited range of introductions are two examples. Our second reason relates to the climates; that of $\mathrm{NZ}$ is maritime and generally equable whilst those in the Australian tropics are much more variable and extreme. In trying to provide pasture species for climatic extremes, for regions which receive an annual rainfall of $500 \mathrm{~mm}$ and others with $7500 \mathrm{~mm}$ some 'general principles' of plant improvement programmes have been fully tested and sometimes found to be wanting. Relevant examples will be discussed, and the extent to which similar breakdowns may occur in NZ should be considered. Before doing so we need to examine some of the historical aspects of our subject.

\section{EARLY PLANT INTRODUCTION AND IMPROVEMENT PROGRAMMES:}

\section{GENERAL PRINCIPLES}

European settlement of Australia and NZ began in warm temperate areas; the introduction of both crop and pasture plants commenced immediately. The temperate areas were initially fortunate in that many of the useful genera and species were already well known; indeed some species of Medicago, Lolium and Phalaris have evolved under the influence of Man as early as 7,500 B.C. (Flannery 1969), and the feeding value of lucerne was known to the Persians and Romans. Plant material, 
albeit of a relatively narrow intraspecific range, was collected at, and disseminated from, centres such as Kew. Not surprisingly the English grasses and legumes gained rapid acceptance in Australia and N'Z and the white clover/ryegrass success story is Well documented. Even the less familiar Mediterranean-type climates of southern Australia were quickly invaded by the annual Medicago and Trifolium species; as in NZ the 'first generation' cultivars were simply selections of naturalised material (Suckling and Forde 1978). A more recent development has been to use newly imported material in breeding programmes designed to improve the strains selected; once again southern Australia has tended to run a parallel course and a general principle of plant improvement, select the best from naturalized material and use newly imported material to improve individual characteristics, was established.

In searching for tropical pasture legumes the general principles developed elsewhere were invoked to, in hindsight, a surprising extent; dry regions supposedly needed an annual 'subclover of the north' whilst for the remaining, wetter areas a perennial 'tropical white clover' was to be found, and bred to suit the various soils and climates. Fortunately, or apparently so, suitable naturalized legumes were in existence in both types of climate, the annual Townsville stylo (Stylosanthes humilis) in the dry and perennials such as Stylo (Stylosanthes guianensis, formerly $S$. guyanensis) and Centro (Centrosema pubescens) in the wetter zones. Following the general principle mentioned earlier, first-generation cultivars were selected from the naturalized populations; more material of these species was then introduced by correspondence. In general such introduced material had little to offer; in Townsville stylo the more vigorous types were similar to naturalized material (Cameron and Edye 1975), whilst the two potentially useful species of Centrosema, C. pubescens and C. brasilianum, showed little variation and were apparently suited only to wet environments (Teitzel and Burt 1976). An impasse had been reached and a new approach was needed if further progress was required. The basis of this had been laid down by Hartley and his pioneering collecting mission of 1945; by the 1960s genetic resource collections were becoming available and the study of the development of one of these provides some interesting lessons.

\section{EARLY USE OF PLANT GENETIC RESOURCE COLLECTIONS IN THE TROPICS : STYLOSANTHES}

By the mid 1960s this collection contained 154 accessions. Some 15 named species were present but most of these were poorly known and even their taxonomic identity uncertain. The success of the two species already mentioned, $S$, humilis and S. guianensis, prompted an examination of the entire collection; the initial objective was to characterize, in terms useful to those involved in plant improvement programmes, the various species and species forms present. Details need not concern us; we simply note that it was necessary to measure a wide variety of morphological and agronomic characteristics and that pattern-seeking methods of analysis were needed to aid the data interpretation (Burt and Williams 1975).

We found three major plant groupings; the first, primarily of $S$. humilis, was of annuals whilst the second, of high yield but low persistence (in the dry tropics), was predominantly of $S$. guianensis. The third group was of high persistence and was of prime importance to us. Here the situation was quite different; the species were variable, there were four types of S. scabra, but each was represented by only a few accessions; types 17 and 18, which yielded the cultivars Fitzroy and Seca, were represented by only 1 and 2 accessions respectively. Furthermore all three accessions had been collected as opposed to, for the remaining members of the species, obtained by correspondence. The other species to yield a cultivar, Verano, was $S$. hamata; once again it was an atypical member of a poorly represented species 


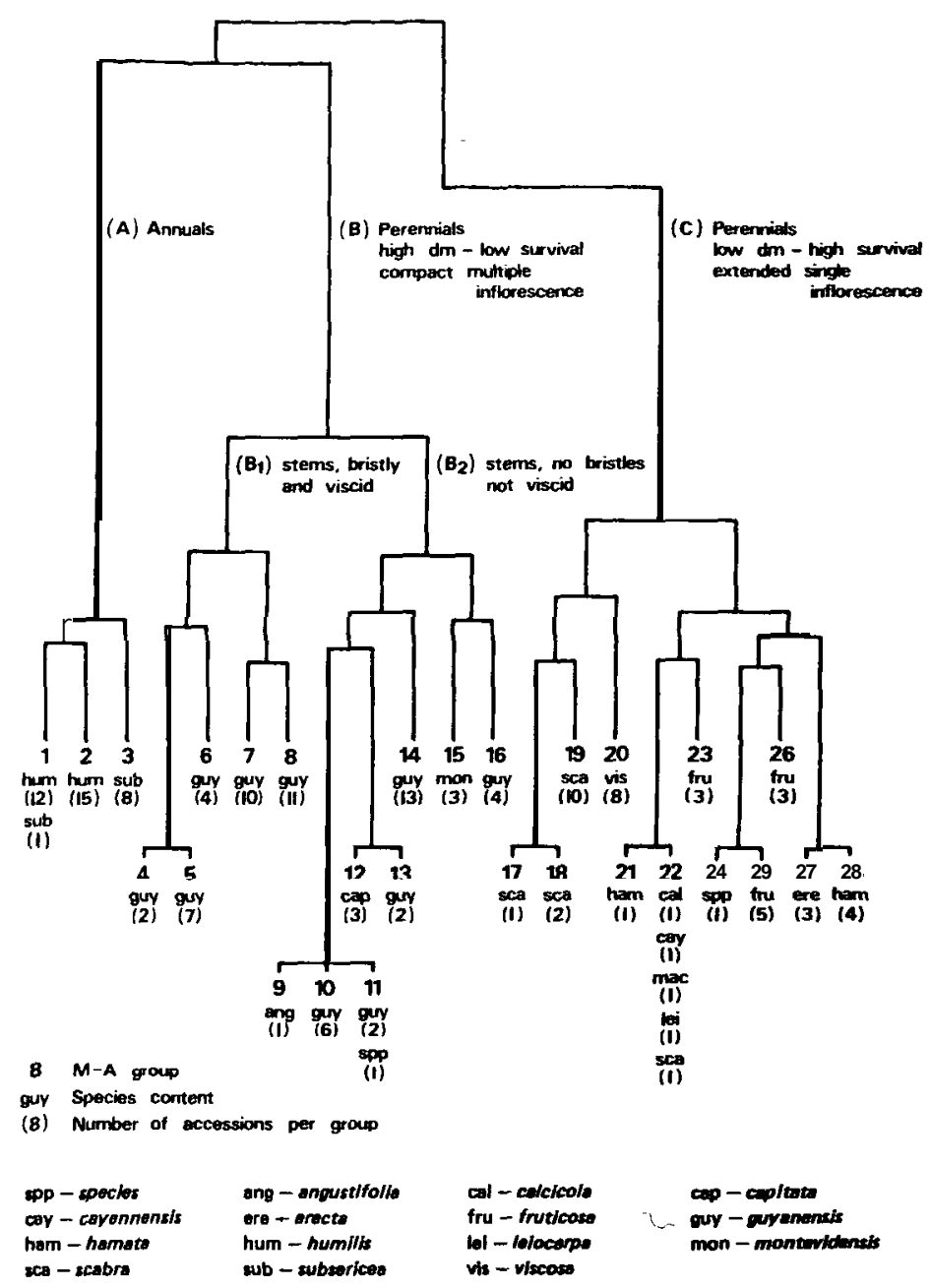

Figure 1: Dendrogram for the Stylosanthes collection produced by pattern analysis. (From Burt \& Williams 1975).

and had been obtained by collection. The more typical members of the species, available by correspondence, were from alkaline soils and failed when tested on the generally acid soils of Australia. These new cultivars, from previously undomesticated species, are far superior to the first-generation cultivars developed from accidentally introduced material.

Legume collections are becoming increasingly available and many are being examined here. To what extent do our findings with the initial Stylosanthes collection apply; do we have, for instance in the Lotus collection, adequate species representation, do we have the various types (now known to correspond to edaphic and climatic ecotypes) to be of use in the different conditions experienced in NZ? Should we import the apparently agronomically attractive Lotus goetzei from the highlands of Africa? Have we analyzed our data in such a way as to reveal the types of 
variation present in our current collections? L. corniculatus grows in the cold, dry highlands of Kashmir (Misri 1981); is this region likely to yield material of interest to us? This last question raises issues involved in the planning of collecting missions and this is our next concern.

\section{COMPARING REGIONS FOR COLLECTION OR EVALUATION}

In developing Stylosanthes we wished to add to our collection of new species, introductions likely to be adapted to the regions for which we required cultivars. We began by comparing the climates from which our successful plants had been collected with those in which they had proved to be of value, a principal coordinate analysis of climatic data aiding the comparison. Adapted plants came, not from climatically homologous regions, but from more stringent conditions; plants for the dry tropics had been collected in more arid environments (Burt et al. 1975).

In the areas so nominated soils had a major influence on plant distribution (Figure 2). On infertile, acidic loams with very low available $P$ levels, only Stylosanthes was found; in the most infertile conditions only S. capitata was common, with S. viscosa, S. scabra and S. hamata becoming more common as fertility improved. Under the latter conditions other genera, Centrosema and Macroptilium, were found.

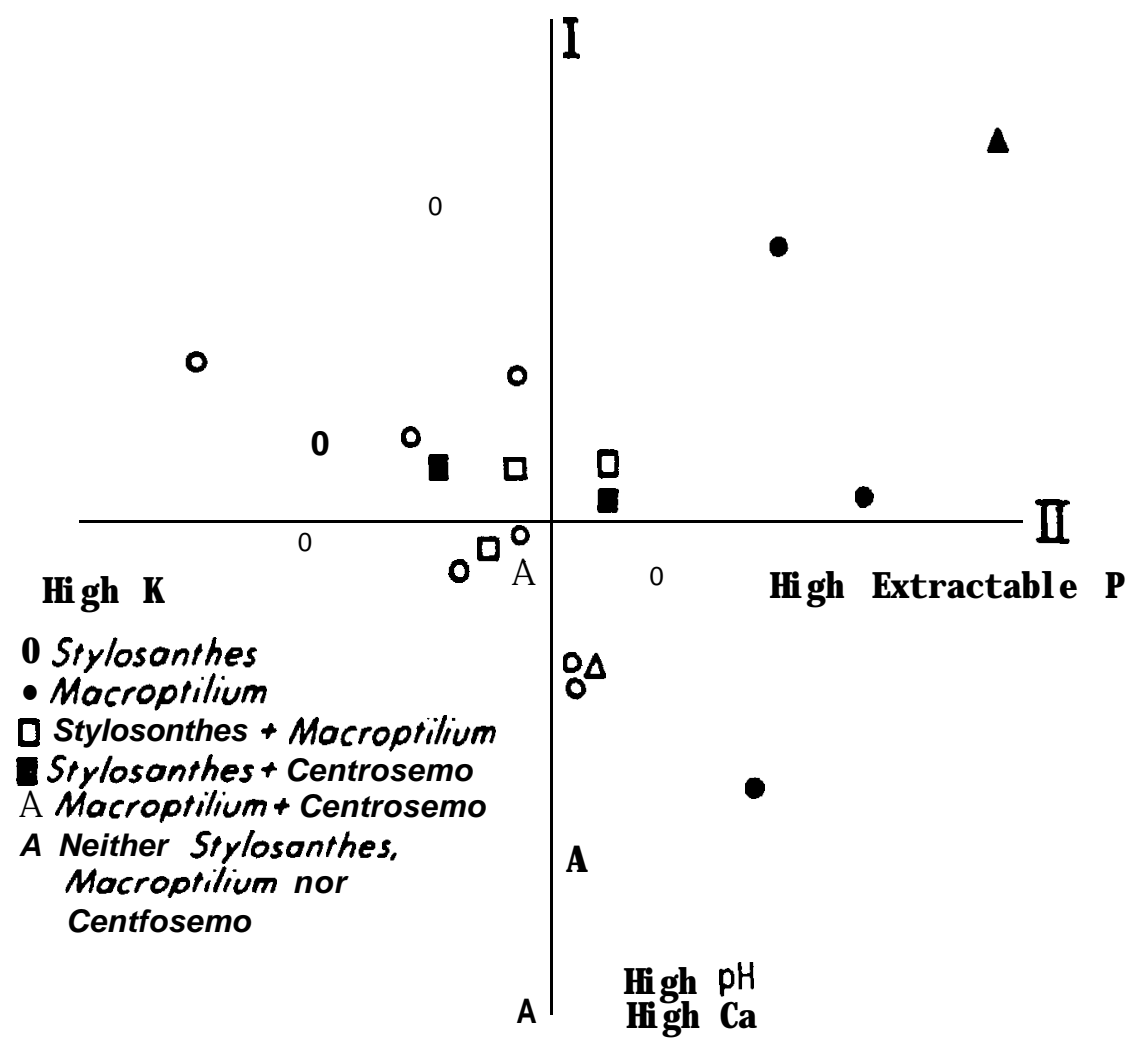

Figure 2: Principal coordinate analysis of 24 surface soils with the predominant genera superimposed on the sites. (From Burt et a/. 1979). 
These edaphic tolerances were reflected in subsequent evaluation studies. Lack of space prevents presentation of results; we simply note that, on acid infertile soils, only S. viscosa and S. scabra flourished whilst S. hamata and S. humilis performed poorly without the addition of superphosphate. Macroptilium and Centrosema accessions died, as surprisingly did S. capitata (Burt unpubl. data); but for different reasons. Date and Halliday (1979) have since shown that both $S$. capitata and its associated Rhizobium require less fertile conditions than those experienced at the test sites.

The selection of species to suit the soil, rather than soil amelioration to suit the plant, may be a plausible practice. In NZ it appears that Lotus thrives in soils too infertile for white clover, and that Dorycnium may provide yet other alternatives. New management practices might well be needed to suit such plants and their associated characteristics, such as high tannin levels in Lotus (see the excellent review by Scott et al. 1985).

\section{FUTURE COLLECTING AREAS FOR SOUTH ISLAND SEMI-ARID AND HIGH COUNTRY}

Genetic resource collections do not automatically cater for every environmental or agronomic situation. If new collections are sought, or existing collections screened for material likely to be of interest, then we might begin asking where the plants which have shown most promise have come from and opt to collect in similar climates elsewhere. In addition to the target species, in our previous example of $\mathrm{S}$. hamata and S. scabra, there is always the chance of finding other species of interest; again in our previous example we found two species of Centrosema growing in semiarid conditions one of which (C. brasilianum) was previously thought to be suited only to high rainfalls and the other (C. pascuorum) has now yielded a cultivar. If we were to collect for Alexandra in the cold, dry deserts of Kashmir, and many species of established interest occur in the region, then might Chesneya, a well eaten leguminous plant in the region, also emerge as a possibility?

Climatically homologous areas can also be chosen using some appropriate system of climatic classification; that produced by Papadakis (1975) serves ou purpose. As examples we will consider only two of the types of climate designated, the 'semi-arid Patagonian' (around Alexandra) and the 'Patagonian grassland' (which corresponds approximately to the high country of the South Island). Notably few climatically equivalent areas are listed and none in the northern hemisphere, the zone from which plant material was originally introduced. Homologous zoñes are to be found in Chile and Argentina and the similarity with NZ highlighted by the success there of introduced Lolium, Medicago and Trifolium species; introductions of these to NZ have shown promise. The native legumes of the region, such as Adesmia, might warrant introduction; the sole accession to be tried has shown many interesting characteristics.

Finally we should mention a method of choosing homologous areas, and one in which we have recently assembled a relevant data bank, based on floristic data; in general terms Hartley (1954) deems to be similar those areas which have similar proportions of their native grass species in various tribes. Recent work (Williams and Burt 1982) has shown that areas with similar percentages, or Agrostological Indices support similar suites of introduced pasture legumes and Hartley (1963) earlier showed that buffel grass (Cenchrus ciliaris) thrives in regions which have similar indices to those in which the species is found naturally. The method therefore produces results for plant introduction purposes.

From published data (Hartley 1954), and using the grass flora of southwest NZ as an example, we again find that Patagonia is the most similar region. Parts of sub- 
coastal and coastal Russia also bear strong resemblances, and Russian material of Trifolium, Onobrychis and Lotus has proved to be useful here.

\section{TOWARDS 2000}

NZ and Australia contain a range of soils and climates which are often quite different from those of our colonial ancestors; indeed some climatic types are relatively rare throughout the world in general. Our plant introduction and breeding personnel have done remarkably well in adapting some of the better known species to these environments and will continue to do so. But there are limits; possibly, as in the tropics, we have reached the limits set by our general rules of plant improvement and should set our horizons more widely.

\section{References}

Burt R.L., Williams W.T. 1975. Plant introduction and the Stylosanthes story. Australian Meat Research Committee Review No. 25, 1-26.

Burt R.L., Reid R., Williams W.T. 1975. Exploration for, and utilization of, collections of tropical pasture legumes. I. Agro-Ecosystems 2: 293-307.

Burt R.L., Isbell R.F., Williams W.T. 1979. Strategy of evaluation of a collection of tropical herbaceous legumes from Brazil and Venezuela. I. Agro-Ecosystems 5: 99-117.

Date R.A., Halliday J. 1979. Selecting Rhizobium for acld, infertile soils of the tropics. Nature 277: 62-64.

Edye L.A.. Cameron D.F. 1975. Comparison of Brazilian and naturalised Australian ecotypes of Stylosanthes humilis in the dry tropics of Queensland. Australlen Journal of Experimental Agriculture and Anima Husbandry 15: 80-87.

Flannery K.V. 1969. Origins and ecological effects of early domestication in Iran and the Near East. In: Ucko P.J., Dimbleby G.S. (Eds.) The Domestication and Exploitation of Plants and Animals. Aldine Publishing Company, Chicago.

Hartley W. 1963. The phytogeographical basis of pasture plant introduction. Genetic Agraria 17: 135-160.

Hartley W. 1954. The agrostological index; a phytogeographical approach to the problems of pasture plant introduction. Australian Journal of Botany 2: 1-21.

Misri B. 1961. A preliminary survey of grasses and legumes of Ladakh. Australian Plant Introduction Review 13: 37.45 .

Papadakis J. 1975. Climates of the world and their potentialities. Buenos Aires, Argentina.

Scott D., Keoghan J.M., Cossens G.C., Maunsell L.A., Floate M.J.S., Willis B.J., Douglas G. 1985. Limits to pasture production and choice of species. In Burgess R.E., Brock J.L. (Ed?.). Using Herbage Cultivars. Grassland Research and Practice Series No. 3. NZ Grassland Association.

Suckling F.E.T.. Forde M.B. 1978. Genetic resources in high-rainfall hill pastures of New Zealand. NZ Journal of Agricultural Research 21: 499-508.

Teitzel J.K., Burt R.L. 1976. Centrosema pubescens in Australia. Tropical Grassland 10: 5-14.

Williams W.T., Burt R.L. 1962. A re-appraisal of Hartley's agrostological index. Journal of Applied Ecology 19: 159.166. 